\section{Regards sur l'économie allemande}

Bulletin économique du CIRAC

$91 \mid 2009$

Varia

\title{
Helmut Schmidt
}

NOACK Hans-Joachim, Helmut Schmidt. Die Biographie / SCHMIDT Helmut, Außer Dienst. Eine Bilanz

\section{(2) OpenEdition}

Journals

Édition électronique

URL : http://journals.openedition.org/rea/3720

DOI : $10.4000 /$ rea.3720

ISBN : 978-2-8218-0878-2

ISSN : 1965-0787

Éditeur

CIRAC

Édition imprimée

Date de publication : 1 mai 2009

ISSN : 1156-8992

Référence électronique

"Helmut Schmidt », Regards sur l'économie allemande [En ligne], 91 | mai 2009, mis en ligne le 20 mai 2009, consulté le 22 septembre 2020. URL : http://journals.openedition.org/rea/3720 ; DOI : https:// doi.org/10.4000/rea.3720

Ce document a été généré automatiquement le 22 septembre 2020

(C) CIRAC 


\title{
Helmut Schmidt
}

\author{
NOACK Hans-Joachim, Helmut Schmidt. Die Biographie / SCHMIDT \\ Helmut, Außer Dienst. Eine Bilanz
}

\section{RÉFÉRENCE}

NOACK Hans-Joachim, Helmut Schmidt. Die Biographie, Rowohlt, Berlin, 2009, 320 p. SCHMIDT Helmut, Außer Dienst. Eine Bilanz, Siedler, Munich, 2e éd., 2008, 350 p.

1 A l'occasion du $90^{\mathrm{e}}$ anniversaire de Helmut Schmidt le 23 décembre dernier, le journaliste Noack qui fut longtemps le chef du service politique de l'hebdomadaire Der Spiegel consacre une sympathique biographie à l'ancien chancelier le plus populaire de la RFA (on y regrettera toutefois l'absence de tout repère historique qui permettrait de mieux situer son parcours dans une période historique particulièrement riche...). A la tête du gouvernement fédéral de 1974 à 1982, Schmidt avait conquis lors de l'inondation de Hambourg en 1962 une réputation 'd'homme de bon sens' qu'il dut mettre à l'épreuve une seconde fois en 1977 , lors de l'enlèvement du patron des patrons (Hanns Martin Schleyer) par les terroristes de la RAF. L'aura de cet elder statesman que sa politique économique et financière faisait passer, aux yeux de certains, pour un froid technocrate en comparaison d'un Willy Brandt qui fut l'artisan de l'Ostpolitik et jouissait de l'estime des artistes, est aujourd'hui plus vivace que jamais dans l'opinion allemande. En cette période où se conjuguent risque terroriste et crise économique, le sens de la mesure et du juste équilibre des décisions qu'incarne celui qui se qualifie luimême de « démocrate social » reste une référence.

On s'en convaincra à la lecture de ses mémoires, dont le titre à lui seul révèle l'humour et la modeste distance de cet homme politique au sens plein du terme : « Hors service. Un bilan ». Le ton est donné dès la préface : «Vers la fin de ma vie, j'ai eu envie de jeter sur le papier ce que je crois avoir appris de la politique au fil des décennies ». Mais qu'on ne s'y trompe pas, cette apparente simplicité se nourrit d'une profonde pensée et, surtout, de valeurs : «La parole et l'action de chaque homme politique doit résister à l'examen de sa propre conscience. [Celle-ci] est pour moi l'instance suprême». Et c'est d'ailleurs une longue réflexion sur l'évolution du monde - et de l'Allemagne dans le monde - qui structure ce 
«bilan ». S'il y revient sur les décisions parfois très douloureuses qu'il eut à prendre, il nous livre aussi (sous le titre «Demokratie bleibt Menschenwerk »: «La démocratie reste le fait de l'Homme»), une analyse du (bon) fonctionnement de la démocratie parlementaire de la RFA. Non sans rappeler à l'intention des acteurs politiques qui auraient déjà oublié que ce modèle n'a été "adopté» (au sens plein) en Allemagne qu'avec la constitution de la RFA : «aucune démocratie n'est parfaite. Et qui l'idéalise à outrance court le risque d'exposer à terme à une rude déception ceux qui se montraient par trop croyants - et [il risque] que ces déçus deviennent ensuite des anti-démocrates ». On lira aussi avec profit la partie consacrée aux « Allemands en tant que voisins » («Die Deutschen als Nachbarn») qui éclaire entre autres l'engagement européen assumé de l'Allemagne. Mais trêve de citations... Ces réflexions de H. Schmidt mériteraient d'être traduites, ce qui permettrait aux Français de mieux comprendre leur principal partenaire dans l'UE. Qu'on se rassure: telle qu'elle est présentée ici par un de ses éminents acteurs, la politique de l'Allemagne n'a rien d'aride ni de mystérieux. Comme l'écrit l'ancien chancelier : « en politique, on n'a jamais affaire qu'à des êtres humains ». (ib) 